\title{
Editorial: Challenges and Opportunities for the EU Common Fisheries Policy Application in the Mediterranean and Black Sea
}

\author{
Simone Libralato ${ }^{1 *}$, Franceso Colloca ${ }^{2,3}$, Ali C. Gücü ${ }^{4}$, Christos D. Maravelias ${ }^{5}$, \\ Cosimo Solidoro ${ }^{1}$, Sebastián Villasante ${ }^{6,7}$ and Massimiliano Cardinale ${ }^{8}$ \\ ${ }^{1}$ National Institute of Oceanography and Experimental Geophysics-OGS, Trieste, Italy, ${ }^{2}$ National Research Council, Institute \\ for the Coastal Marine Environment (CNR-IAMC), Mazara del Vallo, Italy, ${ }^{3}$ Department of Biology and Biotechnology "C. \\ Darwin" BBCD, Sapienza University of Rome, Rome, Italy, ${ }^{4}$ Institute of Marine Sciences, Middle East Technical University, \\ Mersin, Turkey, ${ }^{5}$ Hellenic Centre for Marine Research, Anavyssos, Greece, ${ }^{6}$ Faculty of Political and Social Sciences, \\ University of Santiago de Compostela, Santiago de Compostela, Spain, ${ }^{7}$ Campus Do*Mar-International Campus of \\ Excellence, Santiago de Compostela, Spain, ${ }^{8}$ Department of Aquatic Resources (SLU Aqua), Institute of Marine Research, \\ Swedish University of Agricultural Sciences, Lysekil, Sweden
}

Keywords: common fisheries policy, fisheries management, ecosystem impacts, Black Sea, Mediterranean Sea

\section{Editorial on the Research Topic}

Challenges and Opportunities for the EU Common Fisheries Policy Application in the Mediterranean and Black Sea

\section{OPEN ACCESS}

Edited and reviewed by:

Maria Lourdes D. Palomares, FishBase Information and Research Group, Philippines

*Correspondence: Simone Libralato slibralato@ogs.trieste.it

Specialty section:

This article was submitted to Marine Fisheries, Aquaculture and

Living Resources,

a section of the journal Frontiers in Marine Science

Received: 18 May 2018 Accepted: 07 August 2018 Published: 30 August 2018

Citation:

Libralato S, Colloca F, Gücü AC,

Maravelias $C D$, Solidoro $C$, Villasante S and Cardinale M (2018)

Editorial: Challenges and Opportunities for the EU Common Fisheries Policy Application in the

Mediterranean and Black Sea.

Front. Mar. Sci. 5:299

doi: 10.3389/fmars.2018.00299

\section{INTRODUCTION}

Fishing in the Mediterranean and Black Sea has always been a key economic activity providing livelihood opportunities for hundreds of thousands of people and shaping the culture of the region's coastal communities (Farrugio et al., 1993; Coll et al., 2010; FAO, 2016). From mid 1990s to 2010s, total reported landings fluctuated around 1 million and 500,000 t per year for the Mediterranean and Black sea, respectively (Figure 1). However, landings dropped to 817,000 and 265,000 $\mathrm{t}$ in 2014 in the Mediterranean and Black sea respectively (FishstatJ, GFCM capture production Dataset), while the total value of fish landings was estimated to be at a minimum, around 3.1 billion USD (FAO, 2016).

The negative trends in landings are worrying signals of a critical situation. About $85 \%$ of assessed stocks are fished at biologically unsustainable levels (FAO, 2016), and the overall level of overfishing is around 2-3 times FMSY (European Commission, 2016). The reasons behind these critical conditions are not solely linked to the intense fishing but to the increasing cumulative pressures of a wide range of human stressors that include also aquaculture activities, pollution, habitat degradation, biodiversity loss, and tourism (Coll et al., 2010; Colloca et al., 2013; Piroddi et al., 2017). Climatic induced changes and invasive species are also posing additional threats to exploited marine resources (Libralato et al., 2015; Vasilakopoulos et al., 2017).

There are examples of Mediterranean fisheries exploiting stocks at rates consistent with Maximum Sustainable Yield (MSY; e.g., tuna fisheries) and several fishing fleets are showing important reduction in their capacity (European Commission, 2016; EU Fleet Register). However, the general situation is widely recognized as worrisome and the reduction of fishing mortalityin particular for demersal species-toward a MSY reference value $\left(\mathrm{F}_{\mathrm{MSY}}\right)$ needs to be combined with a substantial change in fisheries selectivity in order to maximize stock biomass, fisheries yield and revenues (Colloca et al., 2013; Vasilakopoulos et al., 2014). Despite recent improvements in 


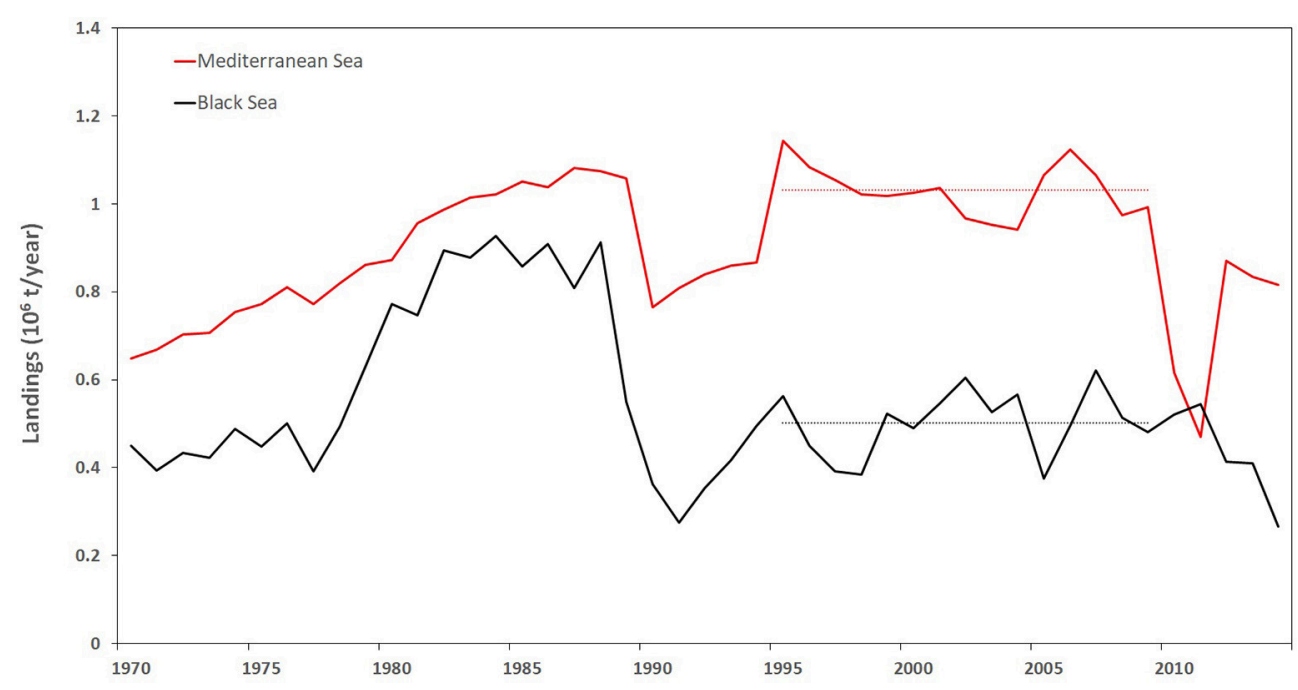

FIGURE 1 | Time series of official landings for the Mediterranean and Black Sea (data from FAO-GFCM Capture fisheries Dataset). Dotted lines indicate the average landings for the period 1995-2009.

the number of stock assessments (GFCM, 2016; STECF, 2016), the number of fish stocks with unknown status remains large (European Commission, 2016), with the possibility that the negative evidences of quantitative stock assessments represent just the tip of the iceberg. With the exception of tuna fisheries, no quotas or total allowable catch (TAC) have been established in the area because of political resistance of the Member States partly motivated with the multi-species nature of the fisheries that are therefore regulated through technical measures and by control of the fleet capacity as proxy of fishing effort (Villasante and Sumaila, 2010; Da Rocha et al., 2012; Carpenter et al., 2016). Furthermore, the widespread small-scale fisheries and the unquantified recreational fisheries are often arguments for high uncertainty on assessments and the difficulties to control and manage Mediterranean and Black Sea wild resource exploitation (Gascuel et al., 2014; Hyder et al., 2017; Piroddi et al., 2017; Selig et al., 2017).

In this context, the application of the Common Fisheries Policy (CFP) in the Mediterranean and Black Sea faces several challenges also because of large ecological, economic, political, and institutional differences across the basin. The challenge of CFP application is exacerbated by the legal/administrative situation, with large areas outside national/EU jurisdictions, by the different development of fisheries that result in fleet capacities highly different on opposite shores of some sub-basins, as well as by uneven monitoring and data availability across the basins that result in situations that hamper sustainable management (Coll et al., 2010; Colloca et al., 2013; Vasilakopoulos et al., 2014; Piroddi et al., 2017).

The latest European Union CFP reform (EC Regulation $\mathrm{N}^{\circ} 1380 / 2013$ ) aims at implementing a community system for conservation of marine fishery resources and for the management of fisheries exploitation in order to guarantee ecological, economic, and social sustainability. These objectives are also a high priority of many national and international regulations and initiatives [e.g., European Marine Strategy Framework Directive (MSFD; 2008/56/EC); Convention of Biological Diversity (CBD), Intergovernmental Platform on Biodiversity and Ecosystem Services (IPBES), United Nations Sustainable Development Goals (SDGs)] which aim to promote the preservation of natural ecosystems and a sustainable use of fishery resources (Piroddi et al., 2017).

Considering past experiences and failures, the CFP envisages the application of the precautionary principle (Garcia, 1995) and the progressive implementation of an ecosystem-based approach for fisheries management (EAFM, Garcia and Cochrane, 2005), through a series of activities that include adoption of conservation measures, delineation of multiannual plans, reduction of unwanted catches through landing obligation, regionalization of the CFP, transferable fishing concessions, and promotion of sustainable aquaculture. Overall, the CFP should ensure that, by 2020 at the latest, fishing mortality rates are set to levels which will rebuild or maintain stocks above biomass levels that could produce the MSY also on the basis of best scientific advice, data collection, and financial supports (EC Regulation 1380/2013). To cover research gaps and current challenges, this Special Issue compiles new empirical evidence and policy recommendations on how scientific outcomes can better inform management decisions in order to create new windows of opportunities to navigate into new sustainable trajectories.

Based on findings from the 16 papers included in this Special Issue, we provide an overview of the main lessons learned and key recommendations for scientists, policy-makers, and practitioners who intend to operationalize the application of the CFP in the Mediterranean and Black sea. We have organized the content of the Special Issue in three thematic areas: (i) trends and ecosystem impacts of fishing activities, (ii) fisheries management, 
technical measures and participatory approaches implemented under the CFP, and (iii) current and future challenges toward the application of the CFP.

\section{THE COMMON FISHERIES POLICY IN THE MEDITERRANEAN AND BLACK SEA}

\section{Trends and Ecosystem Impacts of Fishing Activities}

The first thematic area contains reviews of the state of exploited ecosystems and stocks in the Mediterranean (Colloca et al.; Cardinale et al.) and Black Sea (Oguz), as well analyses including socio-economic fisheries aspects (Sabatella et al.; Raykov and Duzgunes) and physical oceanographic drivers (Guraslan et al.). Colloca et al. carried out a comprehensive review focused on the recent data on Mediterranean fishing fleets and landings, results from stock assessments and ecosystem models, as well as information on invasive species, to provide a diagnosis of the state of resources in different Mediterranean geographical sub-areas. The authors conclude that the current knowledge on fisheries and ecosystems presents a worrisome picture where the effects of poorly regulated fisheries, in combination with growing climate change impacts and the expansion of non-indigenous species, are rapidly changing the structure and functioning of the ecosystem with unpredictable effects on the goods and services provided.

Cardinale et al. analyzed all available stock assessments and effort data for the most important commercial species and fleets in the Mediterranean Sea. The synthesis shows that observed reduction of fishing effort did not result in reduction of fishing mortality. Key reasons for the lack of relationship between nominal effort and fishing mortality for all commercial species can be found in the ineffectiveness of the current effort control system, the continuous non-adherence of adopted management measures to the scientific advice and the inadequacies of existing national management plans. The authors undoubtedly recommend that alternatives management measures as a TAC based system are necessary in the Mediterranean Sea if the EU is willing to move toward the achievement of the CFP's objectives before 2020 .

The economic performance of three important Italian trawl fisheries (Northern Thyrrenian Sea, South of Sicily, Northern Adriatic Sea) presented by Sabatella et al. shows that the nominal fishing effort has decreased remarkably in the last 10 years. The reduction in capacity was promoted by public funding but also by a voluntary departure from the sector due to the general obsolescence of the fishing fleets, the low productivity and the increasing operating costs. In the very last years an increasing trajectory for landings together with the reduction of input costs increased economic profitability of these fisheries. Nevertheless, additional management efforts are needed on an urgent basis in order to ensure the achievement of the management goals defined by the CFP.

The overview of the multiple stressors (e.g., eutrophication, alien species invasions, natural climatic variations) presented in Oguz shows the critical state of important fish stocks in the Black Sea. In this ecosystem, perturbed and degraded since the 1970s, nearly all commercially important fish stocks have been severely depleted due to decades of unsustainable exploitation resulting from excessive fishing capacity and inappropriate fishing practices. The study highlights that the fisheries management and efforts devoted to the rehabilitation from long-term chronic degradation of the food web structure need to be carried out altogether as a part of a comprehensive ecosystem-based management strategy.

The lack of bio-economic studies and common fisheries management plans to control overexploitation and unknown use of the resources in the Black Sea are further emphasized in Raykov and Duzgunes. According to the authors, the future of fisheries management in Black Sea is intrinsically linked with the setting of cross-sectoral policies deal with the cumulative impact of human activities, thus including the Maritime Policy and the MSFD. Under this context, the public and industry are more inclined to support measures upon which they have been consulted, so public participation at the implementation phase is critical.

The potential influence of interannual and seasonal variability of temperature and surface currents, as well as the effect of migration on the success of anchovy overwintering for both the Black and Azov Sea is analyzed in Guraslan et al. by using a Lagrangian modeling approach. Results show that the intensity and timing of autumnal cooling, coupled with current strength, can be of significant importance in determining annual and seasonal variability of migration success of anchovy thus affecting the dynamics of this important commercial species in the Black Sea.

\section{Fisheries Management, Technical Approaches, and Participatory Approaches Implemented Under the CFP}

A set of papers exemplify the potential of different quantitative tools (Quetglas et al.; Russo et al.), of spatial and technical measures (Pérez-Ruzafa et al.; Tsagarakis et al.), as well as of participatory approaches (Lembo et al.; Bastari et al.) in supporting fisheries management.

The application of the EAFM for the bottom trawl and small-scale fisheries in the Balearic Islands (Quetglas et al.) highlights that despite the fishing effort of the bottom trawling has remained relatively low compared to nearby areas, fishing exploitation has produced negative effects on the main demersal resources by altering populations' resilience and by increasing their sensitivity to the climate variability. Quetglas et al. also show that the availability of reliable data is still a challenge because sales outside the official market are important for species with high commercial value. This result reinforces the need to sensitize fishermen about the importance of providing the best data possible-including those for recreational fisheries-to scientists in order to help improving the stock assessment and management. 
Russo et al. used a wide set of individual vessel data, including Vessel Monitoring System (VMS), integrated and compared with overall commercial data, for developing a dynamic spatial assessment for European hake, red mullet, giant red shrimp, and deep-water rose shrimp fisheries in the Ionian Sea. The approach allowed to identify main fishing grounds and to apply the bioeconomic modeling tool (BEMTOOL) whose scenarios highlighted that significant improvements in the exploitation pattern could be achieved by setting up spatial and/or temporal gear-specific bans of the fishing activity, and in particular a 3-month fishing ban for trawlers.

Pérez-Ruzafa et al. made a comparative analysis of specific characteristics and effectiveness of Marine Protected Areas (MPAs) between the North East Atlantic and the Mediterranean Sea. The paper highlights that an optimal management strategy for designing an MPA to protect biodiversity and sustain fishing yields consists of a multi-zoning scheme obtained by combining a network of no-use areas with fished boxes. The study advocates for an optimum size of no-take zones that would range between 600 and 1,500 ha and considers that the spill-over effects on fisheries improves when the distance between MPAs is within a few tens of kilometers.

The implementation of a landing obligation, a key element of the recent reform of the EU CFP [Regulation (EU) $\mathrm{N}^{\circ}$ $1380 / 2013]$, is the focus of Tsagarakis et al. that synthesized the available records of discards in the Mediterranean bottom trawl fisheries. The authors found high discard ratios for 15 species ( 9 bony fishes, three crustacean decapods, and three elasmobranchs), but important target species such as hake, red mullets and highly commercial shrimps showed generally low discard ratios. The authors also highlight that discards for a given commercial species are likely to fluctuate within a fishery, across seasons, years, and regions.

The role of participatory methods and expert consultations' approaches in the assessment of fishery resources is a result of the paper by Lembo et al. The authors explored stakeholders' perception of the objectives and indicators used in the Northern Mediterranean Sea for the monitoring and assessment of ecosystems and marine fishery resources, as well as the stakeholder preferences on alternative management options for improving fishery sustainability. Lemboet al. showed that understanding and incorporating stakeholders' knowledge and views could successfully contribute to effective fisheries management by possibly increasing legitimacy, credibility, and compliance to the EU's CFP.

Local ecological knowledge (LEK) was used in Bastari et al. to understand how benthic invertebrates species have changed in abundance in the central Adriatic Sea since the 1980s. The bryozoan A. semiconvoluta is the only invertebrate species that, based on the fishers' perception, had an increasing trend in the last 40 years with no significant differences between coastal and offshore areas. These results represent a useful example of how LEK provides an opportunity to fill current knowledge gaps when conventional fisheries management assessment method does not provide enough data.

\section{Current and Future Challenges Toward the Application of the CFP}

The last thematic area contains reviews and analyses on the fisheries management systems for Mediterranean (Vielmini et al.; Carpi et al.) and Black Sea (Salihoglu et al.), also in relation with other regulations (Raicevich et al.).

Multiannual management plans (MAPs) are key tools for restoring and managing fish stocks under the CFP, but the review provided by Vielmini et al. shows that such plans have not yet been generally established in EU Mediterranean waters. Despite the fact that policy tools providing frameworks to halt overfishing were already in place during the past two decades (i.e., UNCLOS, FAO Code of Conduct, 2002 CFP), they have been disregarded in the Mediterranean Sea due to lack of implementation and enforcement. Although isolated and not yet enforced, the newly adopted MAP in the Strait of Sicily represents a significant advance.

Carpi et al. synthesized the improvements, flaws and difficulties that have characterized fisheries management in the Mediterranean Sea in the past decade by using anchovy, sardine and Norway lobster fisheries in the Adriatic Sea as example. The authors advocate for the need to adequate assessment models and data, to have regular external review of assessments and to shift from effort control to a quota system in order to align Mediterranean management with the CFP and achieve MSY targets. Moreover, the coordination and role definitions between the General Fisheries Commission for the Mediterranean, the European Commission DirectorateGeneral for Maritime Affairs and Fisheries, the Scientific, Technical and Economic Committee for Fisheries and the Joint Research Centre need to be strongly improved (Carpi et al.).

Salihoglu et al. carried out a quantitative scientific advice on the application of the EU CFP in the Black Sea by analysing the last 15 years and projecting fish stocks under different future climate change scenarios until 2020. Results indicate that the rebuilding of some forage stocks such as anchovy and sprat might not be sufficient to allow for predators like horse mackerel, bonito and bluefish to recover because fishing mortality has stronger impact than food web interactions. Therefore, exploitation levels should be reduced significantly for all species but especially for the piscivorous fish and anchovy for the long-term sustainability of Black Sea fisheries.

The alignment between the Marine Strategy Framework Directive (MSFD) and the CFP is analyzed by Raicevich et al. MSFD criteria and methodological standards were interpreted and applied differently across member States. Therefore authors found lack of coherence in the early implementation of the MSFD, as well as inconsistency in the selection of stocks, application of reference points, and definition of Good Environmental Status. The analysis shows that subregional and regional coordination was not effectively enforced, reducing the likelihood of achieving CFP targets in the Mediterranean by 2020 . 


\section{CONCLUSIONS}

The contributions of this Special Issue, illustrate that there are still critical problems, which undermine the potential recovery of fish stocks in the Mediterranean and Black Sea. Stocks and ecosystems show signs of critical conditions (Cardinale et al. Colloca et al.; Oguz) andeconomic metrics indicate difficulties within the sector (Sabatella et al.). Mixed fisheries of the Mediterranean and Black sea suffer from highly variable discarding practices, whose analysis, however, highlight areas of possible intervention (Tsagarakis et al.).

There is an increasing adoption of updated assessments tools in the area (Quetglas et al.; Cardinale et al.; Carpi et al.) as well as novel quantitative approaches that might provide guidance for evaluating whole ecosystem management options (Salihoglu et al.; Russo et al.; Guraslan et al.). The establishment of MPAs resulted as a valuable tool that might integrate conservation, management and exploitation (Pérez-Ruzafa et al.). Furthermore, data availability is improving and new approaches allow exploiting novel and old information useful to assess and give contribution for the advice (Lembo et al.; Bastari et al.).

Nevertheless, still the acceptance, application and enforcement of regulations seems a problem in the Mediterranean and Black Sea basins (Vielmini et al.; Carpi et al.; Rykov and Duzgunes). Although EU regulations such as CFP and MSFD are possibly converging in goals, their application is clearly jeopardized in the Mediterranean and Black Sea (Raicevich et al.). Overall, the complex social, economic, political, and ecological context of the basin require additional efforts to integrate data across areas and disciplines, to connect people through active participation and stakeholder engagement, and to integrate regulations to define cross-sectoral policies. In spite of the worrying signals for the situation of marine resources in the Mediterranean and Black Sea, which are exacerbated by several stressors and impacts, not solely fisheries, there are also

\section{REFERENCES}

Carpenter, G., Villasante, S., and O'Leary, B. (2016). Europe: keep allowable fish catches sustainable. Nature 531:448. doi: 10.1038/531448b

Coll, M., Piroddi, M., Steenbeek, J., Kaschner, K., Ben Rais Lasram, F., Aguzzi, J., et al. (2010). The biodiversity of the Mediterranean Sea: estimates, patterns, and threats. PLoS ONE 5:e11842. doi: 10.1371/journal.pone.0011842

Colloca, F., Cardinale, M., Maynou, F., Giannoulaki, M., Scarcella, G., Jenko, K., et al. (2013). Rebuilding Mediterranean fisheries: a new paradigm for ecological sustainability. Fish Fish. 14, 89-109. doi: 10.1111/j.1467-2979.2011.00453.x

Da Rocha, J. M., Cerviño, J. M., and Villasante, S. (2012). The common fisheries policy: an enforcement problem. Mar. Pol. 36, 1309-1314. doi: 10.1016/j.marpol.2012.02.025

European Commission (2016). Communication from the Commission to the European Parliament and the Council-Consultation on the Fishing Opportunities for 2017 under the Common Fisheries Policy. Brussels.

FAO (2016). The State of Mediterranean and Black Sea Fisheries. Rome: General Fisheries Commission for the Mediterranean.

Farrugio, H., Oliver, P., and Biagi, F. (1993). An overview of the history, knowledge, recent and future research trends in Mediterranean fisheries. Sci. Mar. 57, 105-119.

Garcia, S. M. (1995). The Precautionary Approach to Fisheries and its Implications for Fishery Research, Technology and Management: An Updated Review. FAO Technical Paper. a series of positive evidences and opportunities. Examples of good practices are emphasized in these contributions altogether suggest a complex set of actions that might work.

These papers also provide a useful contribution for the scientific community, fishing industry and policy makers to jointly address both the challenges and windows of opportunities to create plausible sustainable trajectories over the next decade.

\section{AUTHOR CONTRIBUTIONS}

All authors listed have made a substantial, direct and intellectual contribution to the work, and approved it for publication.

\section{FUNDING}

SL and CS thank the support by the Flagship Project RITMAREThe Italian Research for the Sea-coordinated by the Italian National Research Council and funded by the Italian Ministry of Education, University and Research within the National Research Program 2011-2013. SV thanks the financial aid from the European Commission (Cost Action-Ocean Governance for Sustainability_challenges, options and the role of science) and the ICES Science Fund Project Social Transformations of Marine Social-Ecological Systems.

\section{ACKNOWLEDGMENTS}

We thank all authors and reviewers for their valuable contributions. CM contribution to this work was exclusively completed while working at the Hellenic Centre for Marine Research, Greece. This article in no way expresses his current employer's opinions (i.e., European Commission) nor anticipates its future policy in the area. This Research Topic is dedicated to Prof. Temel Oguz, a brilliant colleague and inspiring mentor who passed away just before the closure of this volume.

Garcia, S. M., and Cochrane, K. L. (2005). Ecosystem approach to fisheries: a review of implementation guidelines. ICES J. Mar. Sci. 62, 311-318. doi: 10.1016/j.icesjms.2004.12.003

Gascuel, D., Coll, M., Fox, C., Guénette, S., Guitton, J., Kenny, A., et al. (2014). Fishing impact and environmental status in European seas: a diagnosis from stock assessments and ecosystem indicators. Fish Fish. 17, 31-55. doi: $10.1111 /$ faf. 12090

GFCM (2016). Working Group on Stock Assessment of Demersal Species (WGSAD). Final report. Scientific Advisory Committee on Fisheries, Rome, 74.

Hyder, K., Weltersbach, M. S., Armstrong, M., Ferter, K., Townhill, B., Ahvonen, A., et al. (2017). Recreational sea fishing in Europe in a global context-participation rates, fishing effort, expenditure, and implications for monitoring and assessment. Fish Fish. 19, 225-243. doi: 10.1111/ faf. 12251

Libralato, S., Caccin, A., and Pranovi, F. (2015). Modeling species invasions using thermal and trophic niche dynamics under climate change. Front. Mar. Sci. 2:29. doi: 10.3389/fmars.2015.00029

Piroddi, C., Coll, M., Liquete, C., Macias, D., Greer, K., Buszowski, J., et al. (2017). Historical changes of the Mediterranean Sea ecosystem: modelling the role and impact of primary productivity and fisheries changes over time. Sci. Rep. 7:44491. doi: 10.1038/srep44491

Selig, E., Kleisner, K., Ahoobim, O., Arocha, F., Cruz-Trinidad, A., Fujita, R., et al. (2017). A typology of fisheries management tools: using experience to catalyse greater success. Fish Fish. 18, 543-570. doi: 10.1111/faf.12192 
STECF (2016). Reports of the Scientific, Technical and Economic Committee for Fisheries-Mediterranean Assessments Part 2 (STECF-16-08). Publications Office of the European Union, 483.

Vasilakopoulos, P., Maravelias, C. D., and Tserpes, G. (2014). The alarming decline of mediterranean fish stocks. Curr. Biol. 24, 1643-1648. doi: 10.1016/j.cub.2014.05.070

Vasilakopoulos, P., Raitsos, D. E., Tzanatos, E., and Maravelias, C. D. (2017). Resilience and regime shifts in a marine biodiversity hotspot. Sci. Rep. 7:13647. doi: 10.1038/s41598-017-13852-9

Villasante, S., and Sumaila, R. (2010). Estimating the effects of technological efficiency on the European fishing fleet. Mar. Pol. 34, 720-722. doi: 10.1016/j.marpol.2009.11.008
Conflict of Interest Statement: The authors declare that the research was conducted in the absence of any commercial or financial relationships that could be construed as a potential conflict of interest.

Copyright (C) 2018 Libralato, Colloca, Gücü, Maravelias, Solidoro, Villasante and Cardinale. This is an open-access article distributed under the terms of the Creative Commons Attribution License (CC BY). The use, distribution or reproduction in other forums is permitted, provided the original author(s) and the copyright owner(s) are credited and that the original publication in this journal is cited, in accordance with accepted academic practice. No use, distribution or reproduction is permitted which does not comply with these terms. 